\title{
Global Equity Markets and International Diversification
}

\author{
Javad Kashefi, Finance, Real Estate, and Law Department, California Polytechnic University, Pomona, CA \\ 91768, dkashefineja@csupomona.edu \\ Gilbert J. McKee, Finance, Real Estate, and Law Department, California Polytechnic University, Pomona, CA \\ 91768,gjmckee@csupomona.edu
}

\begin{abstract}
Interest in global investing has increased tremendously over the last several years. U.S. investors seek to reduce risk by diversifying globally. The risk reduction benefits hinge upon the relationships between U.S. stock market indexes and other international stock market indexes. Portfolio research studies have shown that adding new assets that have low correlation with those already held will enhance the risk to return ratio for the new portfolio. Global diversification may provide a similar risk reduction when an investor's portfolio is expanded to include foreign securities. This study examines relationships between U.S. stock markets and world equity markets to investigate whether international diversification provides additional diversification benefits to U.S. investors.

The data for this study include the annualized equity returns and standard deviations computed for 61 indexes (11 Morgan Stanley Capital International (MSCI) Indexes and 50 national market indexes that were calculated for the period January 1988 to November 2001. Nine portfolio diversification strategies are examined to obtain efficient frontiers. These portfolios are constructed based upon risk-reward ratios (coefficients of variation), systematic risk (beta) and using different MSCI International Market Indexes.

Our analysis suggests that: (1) a portfolio constructed based on coefficients of variation of less than 2 (no index had a ratio of less than 1) as a criterion had the best result; (2) the domestic portfolio $\left(S \& P_{500}\right)$ provided the second best risk-return to the investors; (3) among MSCI Indexes, FAREAST indexes had the worst performance as did China among the 50 countries; (4) the presumption that low correlations (less than 0.5) would be an attractive means of reducing the portfolio risk did not produce the best risk-return trade off; and (5) the size of the coefficients and long-term stability of the correlations between country indexes have increased.

Finally, the efficient frontier's point of inflection for this study (January 1988-November 2001) for most of the portfolios occurred at more than 45 percent investment in U.S. market. This result is consistent with prior studies that found the point of inflection for a portfolio consisting of U.S. and foreign stock markets generally occurs at about 40 percent. Our result is dramatically different from the Sharma, Obar, and Moser (1996) study that concluded the point of inflection for their four portfolios occurred with only 10 percent invested in the U.S. market.
\end{abstract}

\section{Introduction}

The case for diversification was made in Markowitz's seminal article "Portfolio Selection" that presented the theory of efficient diversification of investments and lead to the development of Modern Portfolio Theory. Numerous studies of portfolio diversification have followed that examine various investment strategies that are evaluated based on the risk and return trade-off that is represented graphically as the efficient frontier. For example, Solink (1974) examined the benefits of diversification for a number of major stock markets. His analysis showed that investors could diversify further to reduce portfolio risk by investing internationally. Eaker and Grant (1990) show that diversifying internationally with or without currency hedging will result in higher rate of return on portfolio than a simple portfolio of domestic securities. Their result showed that portfolios coupled with forward hedging tend to have a dominant efficient frontier compared with portfolios that do not involve hedging. Jorion (1989) and Grauer and Hakansson (1987) showed that a combination of foreign equities and bonds dominated the U.S. markets on both return and risk dimensions. Sharma et al. (1996) examined several portfolio diversification strategies based on lowest market co-movements and lowest currency movements. Their findings were that the point of inflection occurred at a very high proportion of foreign investment for the 
1988-1993 period and that currency hedging did not play a very important role in affecting the expected returns of the portfolios.

Given all this evidence supporting international diversification as a portfolio strategy, have changes in international capital markets affected today's strategies? Is it still possible to enhance risk-return relationships by including foreign securities in a portfolio?

The studies cited above predate (before 1996) reforms in many of the world's financial markets. Globalization of financial markets has furthered the interdependence of capital markets as illustrated by the effects of the Mexican Peso crisis, the Russian ruble crisis and the Asian currency crisis. The authors feel that a new study of these relationships will provide guidance to U.S. investors' efforts to realize risk reduction through international diversification and to identify criteria for portfolio selection.

\section{Methodology}

The case for international diversification is predicated upon a better (smaller) ratio of risk-to-reward than is obtainable with a purely domestic portfolio. This may be achieved through a higher expected return for a given level of risk or a lower level of risk for given rate of return.

Our study seeks to determine if strategies involving international portfolio diversification could provide superior risk-return results as compared to a purely domestic investment strategy. The analysis began with an examination of the cross correlations between international markets from January 1988 to November 2001 (January 1988 was selected to exclude the October 1987 U.S. market crash). Higher variability for a period will affect (increase) correlations and distort the results.

U.S. investors can define an efficient asset allocation between U.S. market and international markets by using the Markowitz mean-variance efficient assets allocation model. In this study nine equally-weighted portfolios are constructed. The performance of all nine portfolios is presented in Table 7. The first four portfolios are constructed as combinations of: the MSCI World Index, MSCI Euro Index, MSCI Emerging Market Index, and MSCI Nordic Index with the U.S. S\&P $\mathrm{P}_{500}$. Portfolios five and six are based on the coefficient of variations for national market indexes. Portfolios seven and eight are based on the betas of the national market indexes. The beta for each country is estimated using the MSCI World Index as the proxy for the market portfolio. The final portfolio consists of markets that are selected based on their market co-movements. The criterion for this portfolio was to choose those markets (among the 50 national markets) that had a correlation coefficient of less than 0.50 with the U.S. market.

\section{Data}

The monthly market returns data for this study were downloaded from MSCI Data.com on December 5, 2001 and cover the period January 1988 to November 2001. The data is further partitioned into two sub-periods. The sub-periods encompass January 1988-December 1995 and January 1996-November 2001. The latter period is a time period during which economic and financial reforms were taking place around the globe. Local currency returns have been converted to dollar returns to facilitate comparisons with returns in U.S. stock markets and reflect the viewpoint of U.S. investors. The methodology used by Morgan Stanley Capital International to compute the indexes can be accessed at www.MSCIDATA.Com/EquityMethodology.

\section{Empirical Results}

\section{Correlations Between Equity Returns}

Tables 1 and 2 (attached as appendix A) present correlations among the world's major equity markets (50 countries) and selected MSCI Indexes for the sub-periods. Table 3 (appendix A) lists correlations for the whole period. A review of the three tables reveals that most of correlations are positive in sign and low with only a few negative in sign. The average correlation coefficient for the period (1988-2001) is 0.31 with an average correlation coefficient of 0.25 for the first sub-period (January 1988 to December 1995) and 0.36 for the most recent sub-period (January 1996 to November 2001). The correlations display some anticipated properties, i.e. higher correlations among developed countries and higher correlations for nations that are geographically proximate to one another. This result parallels other studies. For example, Solink (1988) studied the 15-year period 1971-1986 and found an average correlation of 0.35 between countries. Similarly, Eun and Resnick (1988) found an average correlation of 0.41 for the period from 1973-1982. Hunter and Cogin (1990) in a later study calculated an average correlation coefficient of less than 0.55 for period from 1970-1986. 
Table 4 (presented below) lists the correlation coefficients for the U.S. market index and other indexes for both the sub-periods with their respective ranks. Of the 53 indexes for which there are correlations for both sub-periods, 47 have higher correlations for the 1996-2001 sub-period while only 6 have lower correlations. The U.S. equity market shows a high correlation with Canada (0.81), the United Kingdom (0.70), and the Euro (.73), and a low correlation with India (0.21), Pakistan (0.17) and Peru (0.20).

Solnik, Boucrelle, and Le Fur [1996] studied the correlation of major foreign markets with the U.S. market. The foreign markets included Germany, France, the United Kingdom, Switzerland and Japan. They found the correlation of individual foreign stock markets with the U.S. stock market had increased slightly over the past thirty-seven years although no trend was discernible over the last decade of their study. This study also revealed that correlation fluctuates widely over time and increases in periods of high market volatility. The ranks for the correlation coefficients that are presented in Table 4 were used to calculate a rank order correlation coefficient. The rank order correlation coefficient is 0.69 and suggests strong continuity in the long-term relationship between these equity markets. This observation is consistent with other studies notably Michaud (1996) and Solnik (1996) that estimated the monthly correlations between the U.S. market and a sample of developed countries.

\section{[Insert Table 4]}

Table 5 and 6 present a comparison of Michaud and Solnik's results with ours. We show that the interrelatedness between the U.S. market and the sample of developed countries has been strengthening. For example, financial markets that were relatively highly correlated with U.S. in the earlier period such as Canada and the United Kingdom had even higher correlation coefficients in the later period, 0.64 to 0.81 (Canada) and 0.59 to 0.70 (U.K.). The rank order correlation between the two sets of correlation estimates for developed countries is 0.72 . This is the same result that Michaud (1996) found for the period 1959 through 1995. Low correlations between countries are the key to benefiting from international diversification. This analysis indicates that financial markets are becoming increasingly interrelated over time. With the recent reforms enacted in the individual financial markets it can be argued that the world equity markets that are subject to similar macroeconomic factors have become highly synchronized. With the increased interdependency of national economies, it is likely that these correlations will, at a minimum, remain high and foreclose the opportunity of risk reduction through international diversification.

\section{[Insert Table 5]}

[Insert Table 6]

\section{Analysis of Risk and Return}

The statistics used for our analysis of risk and return are presented in Table 7. The data summarizes the performance for 11 index groups and 50 countries for each sub-period and the entire period. The statistics that were computed include annual return, standard deviation, coefficient of variation (CV), and beta. Betas are calculated using the MSCI World Market Index to represent the "market". The last column shows the correlation coefficient for each market and the MSCI World market index.

An examination of the MSCI market index data on returns for the study period shows that the best (in terms of annual rates of return) performing index over this period was the Nordic Index with a return of 14.67 percent. The worst performing index was the Far East with a return over the period of -0.60 percent. Volatility (risk as measured by standard deviation) was lowest for the North American Index with a standard deviation of 14.12 percent. The Emerging Eastern Europe Index was the most volatile with a standard deviation of 38.14 percent. The relative equity risk as measured by the coefficient of variation (CV) for the 9 indexes with positive returns is above 1.0 indicating that the risk was greater than the return. Relatively low CV's were calculated for the North American 1.13 and Nordic countries 1.51 and while the Pacific had the highest CV (112.55) over the period.

\section{[Insert Table 7]}

The country data presented in Table 7 is categorized into four regions: Europe, Asia/Pacific, America and Middle East/Africa. The annual rate of return and the standard deviation for selected countries can be used to 
illustrate the risk return tradeoff. The national markets (European Region) in Russia, Poland and Turkey had the highest standard deviations over the study period and investors realized high annual returns. Belgium, Switzerland, Netherlands and the U.K.(European Region) had comparatively low standard deviations and low annual rates of return. In the America region Argentina, Brazil and Mexico had the highest standard deviations and returns while the U.S. and Canada exhibited comparatively low the standard deviations and corresponding returns. For all of these markets we observe the expected relationship between annual rate of return and the risk with the riskier assets-those with higher standard deviations- generating a higher rate of return

The best regional performance as measured by the lowest CV (1.88) was America. This region also experienced the highest return (19.98\%). The worst regional performance was the Asia/Pacific region with a CV of 7.85 and a return of $4.57 \%$. This contrast reflects the Asian currency crisis that has gripped the Asian countries over the last several years. A comparison of standard deviations between the two sub-periods indicates that with exception of the America region volatility has increased. During high volatility periods the international correlations for stocks would be expected to increase. The comparison of the sub-period correlations in Table 4 confirms this expectation.

\section{Portfolio Strategies}

This study also examines the portfolio choice of an U.S. investor who seeks to make an efficient allocation between the U.S. market and international markets. The question to be addressed is whether the investor would have benefited by holding an international portfolio than a portfolio of U.S. Stocks? To explore this question, we have created nine portfolios that examine the benefits of international diversification. Table 8 enumerates nine different portfolio strategies. The portfolios are constructed from an equally-weighted portfolio of the non-U.S. markets that is combined with the U.S. index. The weights represent the weight of the U.S. index in the respective portfolios. The return, standard deviation and correlation coefficient are used to determine the efficient set of portfolios.

\section{[Insert Table 8]}

The first four portfolios are combinations of MSCI World Index, MSCI Euro Index, MSCI Emerging Market Index, and MSCI Nordic Index with U.S. S\& $\mathrm{P}_{500}$. To construct the efficient frontier, we started with 1.0 weight (100 percent) in the U.S. market and gradually increase the respective MSCI Index weight to 1.0 (zero percent in the U.S.). Figures 1 through 4 show the results. Note that the risk of Portfolio 1 U.S.- World Index is reduced until 45 percent of the portfolio is invested in the U.S. market. For Portfolio 2, U.S.-Euro Index, the minimum risk occurs when 70 percent of the portfolio is invested in the U.S. market. These percentages are obtained from the point of inflection for the efficient frontiers and are comparable to other studies of international diversification. The notable exception is the Sharma (1996) study where the point of inflection occurred at 10 percent investment in the U.S. market.

The efficient frontiers for Portfolio 3 through 8 do not have points of inflection. Portfolio 9 is constructed based on correlation coefficients of less than 0.5. The inflection point for this portfolio is about $75 \%$. The efficient frontiers for Portfolio 3 and Portfolio 6 are illustrative of the dominance concept that would result in a recommendation of a $100 \%$ U.S. market portfolio.

\begin{tabular}{lc} 
[Insert Figure 1] & [Insert Figure 2] \\
[Insert Figure 3] & [Insert Figure 4] \\
[Insert Figure 5] & [Insert Figure 6] \\
[Insert Figure 7] & [Insert Figure 8] \\
[Insert Figure 9] & \\
\hline
\end{tabular}

The efficient frontiers portray the dominance of the U.S. market over non-U.S. markets for four of the nine portfolios constructed for this study. U.S. investors would benefit from international diversification. If instead, investors base their portfolio choice on the Return to Risk ratio of the different portfolios choices the U.S. 
portfolio has the highest value and implies that international diversification may be less desirable for U.S. investors.

\section{Conclusion}

In this study we sought to determine whether international diversification would provide a better risk-return strategy for the U.S. investor than investing in U.S. markets. The returns on various international portfolios were contrasted with returns in the U.S. markets. The U.S. stock market had superior equity returns than equity returns in the Asia/Pacific, Middle East and Africa and EAFE regions that were achieved with lower risk. While the Nordic countries index provided a higher return than the other MSCI Indexes the return came with a corresponding higher risk. For the US investor the benefits of international diversification appear relatively small.

\section{Suggestions for Further Research}

The study constructed nine equally weighted portfolios. A future study might examine market value weighted portfolios. The results for the Asia/Pacific portfolio would be expected to change as the region moved beyond the Asian currency crisis. Data was unavailable for some countries in the Middle East/Africa and the Eastern European Regions for the earlier sub period. The study period could be changed to refine the comparisons.

\section{REFERENCES}

1. $\quad$ Eaker, Mark R., and D. Grant, "Currency Hedging Strategies for Internationally Diversified Portfolios," Journal of Portfolio Management, Fall, 30-33, 1990.

2. Eun, Cheol and Bruce Resnick, “Exchange rate Uncertainty, Forward Contracts and International Portfolio Selection," Journal of Finance, March 22-31, 1988.

3. Grauer, R. and Nils Hakaansson, "Gains from International Diverification: 1968-85 Returns on Portfolio of Stocks and Bonds,” Journal of Finance, July 721-738, 1987.

4. Hunter, John E., and Daniel Coggin, "An analysis of The Diversification Benefit From International Equity Investments," Journal of Portfolio Management, Fall, 33-36, 1990.

5. Jorion, Philippe, "Asset Allocation With Hedged and Unhedged Foreign Stocks and Bonds," Journal of Portfolio Management, Summer, 49-54, 1989.

6. Markowitz, Harry, "Portfolio Selection," Journal of Finance, March , 77-91, 1952.

7. Markowitz, Harry, Portfolio Choice: Efficient Diversification of Investments, John Wiley \& Sons, New York, 1959.

8. Michaud, Richard Q., Gary L. Bergstrom, Ronald D. Frashaure, and Brian K. Wolahan, "Twenty Years of International Equity Investing," Journal of Portfolio Management, Fall, 9-22, 1996.

9. Sharama, Maneesh, Ruth Obar, and Ernest Moser, “Efficient Frontier: The Surprising Results of Shorter Relationships," Multinational Business Review, Spring, 1-8, 1996.

10. Solnik, Bruno, "Why Not Diversify Internationally Rather than Domestically?" Financial Analysts Journal, JulyAugust , 48-54, 1974.

11. Solnik, Bruno, International Investments, Addison-Wesley, Reading, 1988.

12. Solnik, Bruno, Cyrill Boucrelle, and Yann Le Fur, “ International Market Correlation and Volatility,” Financial Analysts Journal, (September/October), 17-34, 1996.

13. MSCI Data.Com (2001). "Index Coverage". Downloaded from the World Wide Web on December 5, 2001.

\section{Appendix A}

[Insert Table 1]

[Insert Table 2]

[Insert Table 3] 
